\title{
Bone Healing by the Use of Intramedullary Pinning in Dogs
}

\author{
Bouknine Asma*, Boudra Abdellatif, Hamdi Mohame, Hamri Mokhtar, Rezki Hamza \\ Institute of Veterinary Science, University of Tiaret, Tiaret, Algeria \\ Email: ${ }^{*}$ asmabouknine@gmail.com
}

Received 15 April 2014; revised 20 May 2014; accepted 14 July 2014

Copyright (C) 2014 by authors and OALib.

This work is licensed under the Creative Commons Attribution International License (CC BY). http://creativecommons.org/licenses/by/4.0/

(c) (i) Open Access

\section{Abstract}

Femur is the most commonly fractured bone in dogs. This work is interested in the technical aspects of ostheosythesis with intramedullary pinning, and a quality of functional and bone healing results. Our experimentation involved the use of four healthy male dogs, by causing a transverse osteotomy in the mid shapt of in the left femur, with clinical and radiological follow established. Our results show that the intramedullary pinning is the most secure method and gives fewer complications with second bone consolidation. At the end of our study, we have concluded that using intramedullary pins is safe, economical and successful treatment method if basic principles of repair are used.

\section{Keywords}

Femur, Intramedullary Pinning, Consolidation

Subject Areas: Anatomy \& Physiology, Orthopedics

\section{Introduction}

The femur fracture in canine was frequently recorded as compared to other long bone fractures. To treat fractures of long bones of small animals both conservative and operative methods are used, although numerous options are available for fracture treatment, surgical internal fixation various intramedullary pin are used [1].

Stability in orthopedics is defined as the degree of displacement between the fragments involved in a fracture and stiffness as the capacity of the implant to oppose deformation [2].

Intramedullary pinning acts primarily as internal splint of medullary canal of long bone that shares loading with bones maintain axial alignment of the fracture and resists bending forces in all directions applied to the bone [3].

The objective of the present study was to evaluate the femur fractures and treatment options in dogs by intramedullary pinning fixation.

${ }^{*}$ Corresponding author. 


\section{Material and Methods}

Four healthy male dogs ranging in age from 5 to 12 months and weighing 12 to 16 kilograms were used in the experiment. All dogs were kept under the same managemental and nutritional regimens during the experiment. Food was withheld 6 - 8 hrs before the operation. Each dog was premedicated with I/M injection of chloropromazine hydrochloride in a dose of $1 \mathrm{mg} / \mathrm{kg}$. Intravenous injection of atropine sulphate (0.04 mg/kg body weight); buprenorphine IM injection ( $0.02 \mathrm{mg} / \mathrm{kg}$ body weight), and then general anesthesia was conducted by I/V injection of tilitamine-zolazepam (5 mg/kg body weight). The site of operation (lateral aspect of the left thigh) was aseptically prepared. In shape skin incision was made over the cranial border of the femur bone from the subtrochantric area to the femoral condyles. Separation between the biceps femoris muscle caudally and the vastus lateralis was done to expose the femoral shaft. The left femur of all animals was experimentally fractured transversally by using a wire saw in the mid-diaphysis under constant cooling with a $0.9 \% \mathrm{NaCl}$ solution with antibiotic then the femur were fixed by intramedullary pinning by retrograde manner and renforced by hemicerclage wire (Figures 1-4).

Dogs were clinically observed daily during the study period for recording any postoperative complications No postoperative immobilisation was used, all dogs received antibiotic during 10 days.

A radiograph examination is made room immediately after surgery to enjoy a good quality of osteotomy, the correct position of the implants and the absence of intraoperative fractures. To assess the degree of bone healing, radiographs were taken at $1,2,3,4,5,6$ weeks postoperatively until bone healing.

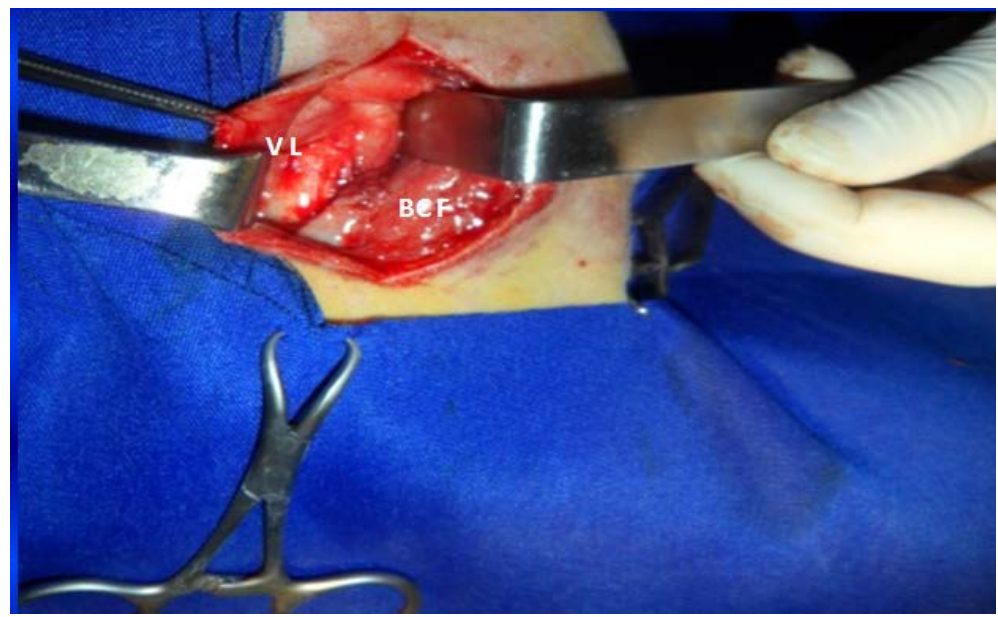

Figure 1. Separation between two muscles (vastus lateralis and biceps femoris).

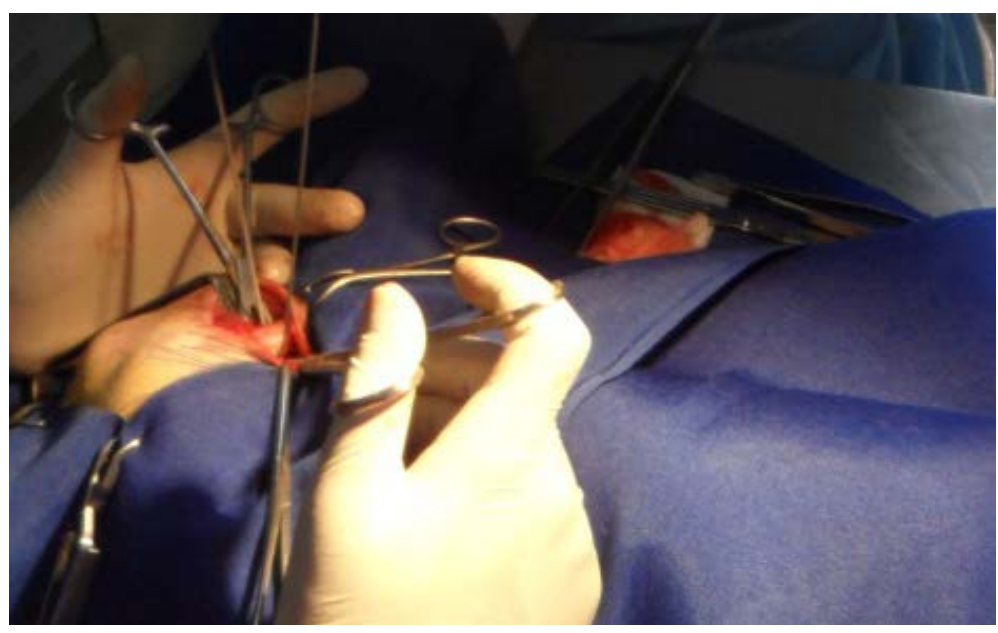

Figure 2. Transverse osteotomy. 


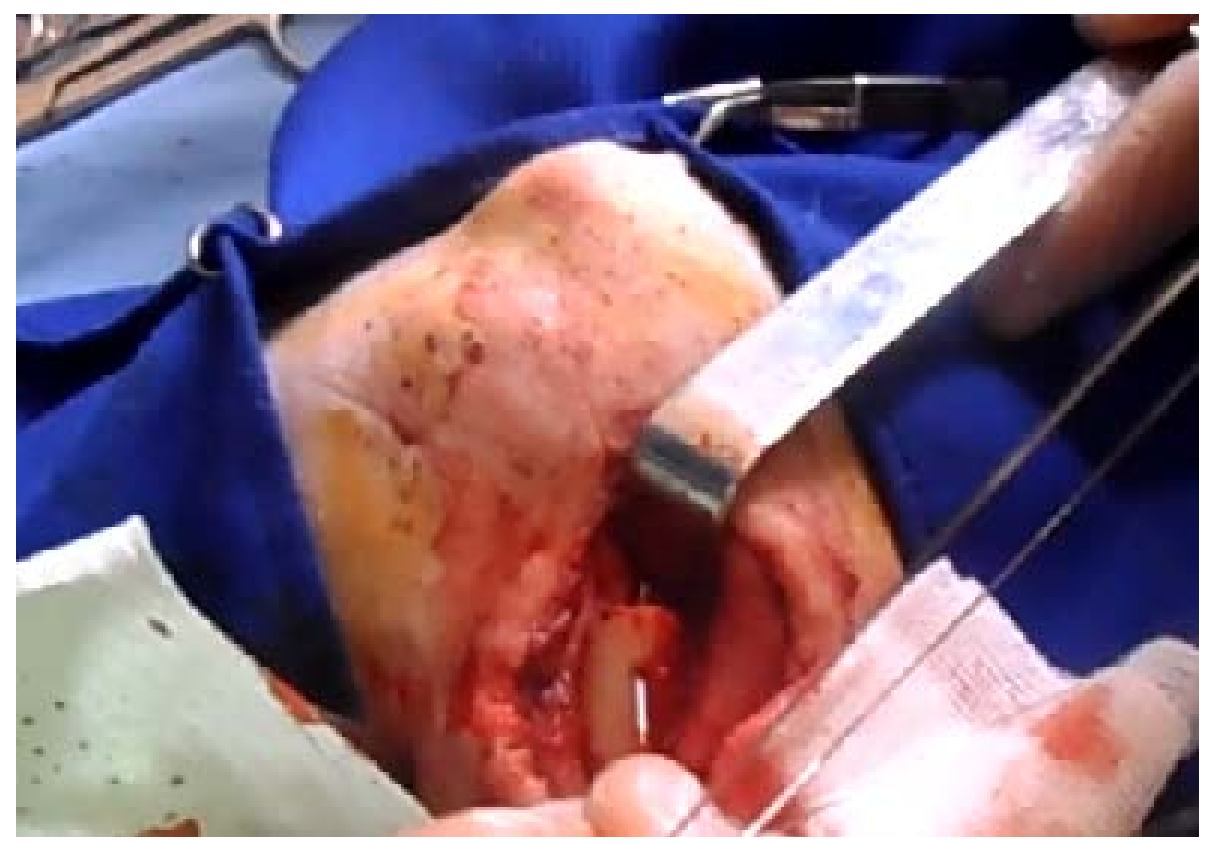

Figure 3. Penetration of metallic wire.



Figure 4. Introduction of pin in medullary canal.

\section{Results}

Osteosynthesis performed under general anesthesia effect, allowed good muscle relaxation and a satisfied analgesia throughout the procedure. The average time for setting up an intramedullary pinning fixation is $45 \mathrm{~min}$. In all animals, the sequence of interventions revealed no complications, and the awakening took place peacefully. During the post-operative follow, we found the presence of edema at the operative site in all animals. From a functional point of view, recovery and return to function of dogs treated with intramedullary pinning took place gradually (Table 1). For the group treated by intamedullary pinning, all animals showed progressively dense of periosteal reaction at the $2^{\text {nd }}$ week. At the $5^{\text {th }}$ week, with the beginning of periosteal callus bridging formation from the third week, of full training callus generally after one month follow up (Figure 5, Figure 6). It was the beginning of callus formation but infection has hampered bone consolidation in one dog (Figure 7). 
Table 1. Clinical evolution of support of animals during following period ( station and walking).

\begin{tabular}{|c|c|c|c|c|c|c|c|c|c|c|c|c|}
\hline \multirow[b]{2}{*}{ Support } & \multicolumn{2}{|c|}{$\mathbf{1}^{\text {st }}$ WEEK } & \multicolumn{2}{|c|}{$2^{\text {nd }}$ WEEK } & \multicolumn{2}{|c|}{$3^{\text {rd }}$ WEEK } & \multicolumn{2}{|c|}{$4^{\text {th }}$ WEEK } & \multicolumn{2}{|c|}{$5^{\text {th }}$ WEEK } & \multicolumn{2}{|c|}{$6^{\text {th }}$ WEEK } \\
\hline & S & W & $\mathrm{S}$ & $\mathbf{W}$ & $\mathrm{S}$ & $\mathbf{W}$ & S & $\mathbf{W}$ & S & $\mathbf{W}$ & S & W \\
\hline Case $\mathrm{N}^{\circ} 1$ & \pm & - & \pm & - & + & + & ++ & ++ & ++ & ++ & ++ & ++ \\
\hline Case $\mathrm{N}^{\circ} 2$ & \pm & - & \pm & - & + & - & - & - & - & - & - & - \\
\hline Case $\mathrm{N}^{\circ} 3$ & \pm & \pm & + & \pm & + & \pm & \pm & \pm & ++ & ++ & ++ & ++ \\
\hline Case $\mathrm{N}^{\circ} 4$ & ++ & + & ++ & ++ & ++ & ++ & ++ & ++ & ++ & ++ & ++ & ++ \\
\hline
\end{tabular}

S: station, W: walking. \pm : Lack of support. \pm : Very light support. +: Lightweight support. ++: Comprehensive support.

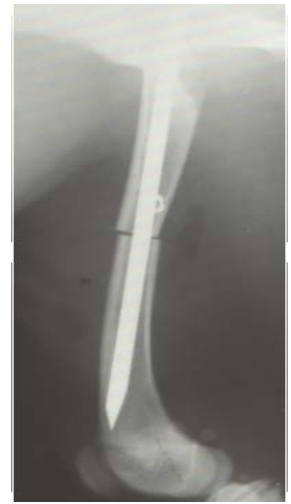

(a)

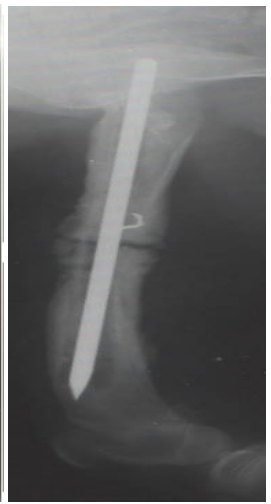

(b)

Figure 5. Immediately postoperative radiography of case $\mathrm{N}^{\circ} 1$ (a), showing presence of pin which happen until the distal epiphysis, and clear line (b), showing the callus formation.

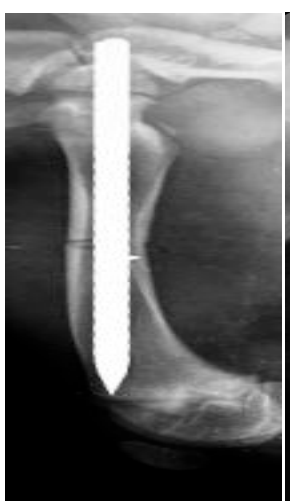

(a)

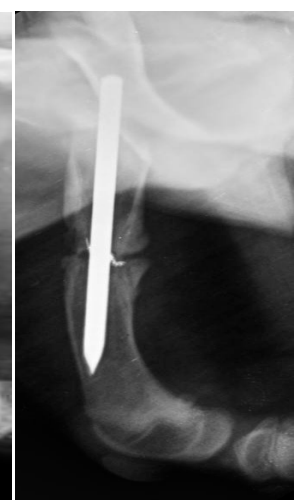

(b)

Figure 6. Immediately postoperative radiography of case $\mathrm{N}^{\circ} 4^{\circ}$ (a) showing presence of pin which happen until the distal epiphysis, with a good alignement of two abouts, and secondary ossification at fourth week (b).

\section{Discussion}

There are three areas of osteognic potential in the healing of any diaphyseal Fracture: the periosteal reaction, the endosteal callus, and time fractures hematoma.

In our study, Fractures treated by intramedullary pinning must unite by peripheral callus because the pin blocks the endosteal callus and new bone does not develop from the vascular cortical ends. There is little doubt that insertion of an intramedullary pin is basically unphysiological because it destroys the medullary blood supply and a large part of time blood supply of the cortex and prevents formation of endosteal callus [3]. However, 


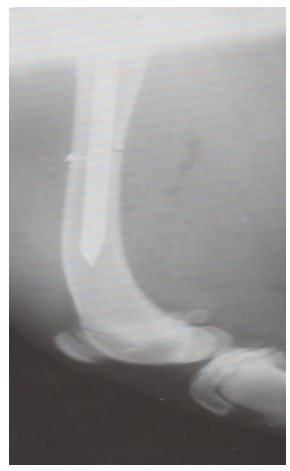

(a)

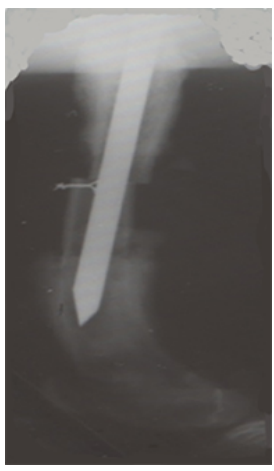

(b)

Figure 7. Radiography of case $\mathrm{N}^{\circ} 3$ showeing alignement of two abouts (a), (b) a beginning of callus formation.

it has been demonstrated that the marrow is able to regenerate vascularisation after one week and to irrigate the bone cortex, with the exception of areas where it is in direct contact with the nail [4]. Moreover, the insertion of intramedullary pin promote bone healing even by bringing in contact with the bone fragments, pluripotent cells derived from bone marrow [5].

A complication in the assembly is recorded osteomylitis, it results in a diffused light on the radiograph. The bone infection in case $\mathrm{N}^{\circ} 2$, caused the release and migration of pin, from the medullary canal of the bone to the outside. A modification of support within the same group were found, the support case $\mathrm{N}^{\circ} 1,3$ and 4 was been early compared case $\mathrm{N}^{\circ} 2$, which shows two complication which are osteomyelitis, and migration of pin.

On radiological features of fractured femur in dogs at scheduled intervals following reduction, revealed callus formation on day 28 post treatment. The 35-day radiograph indicated the beginning of reabsorption of excessive callus, reduced periosteal reaction and process of remodeling of new bone. Radiographs on day 60 (Figure 8) revealed completion of the reparative process supported by reabsorption of excessive callus and disappearance of periosteal reaction with a good healing of bone.

This coincides with a good clinical recovery and full support of dogs was observed during the $4^{\text {th }}$ week (Table 1 ). The Case $\mathrm{N}^{\circ} 4$ had delayed consolidation report, relative cases $\mathrm{N}^{\circ} 1$ and 3 whom are the same age, this is due to the turbulent behavior of the animal and its movement who were responsible for the delay of consolidation and secondary ossification; the migration of pin before the complete consolidation showed an angulation of the bone in the dog $\mathrm{N}^{\circ} 2$. This complication is the essential defect of intramedullary pinning recorded during our study. According to Fossu, 2007 [5], the micro movements of the pin caused by the inequality between a pin and the diameter of the medullary canal, so, are responsible for the migration of the pin. This has necessitated, that is why, we are used, a complementary fastener as hemi-wire to increase the rotational and axial strength. This difference in diameter, according Duhautois, 1993 [6]; back to the fact that changes in diaphyseal sections and the curvature of the bone in the large dog, do not allow the pin to hold the entire medullary canal, by cons, the joining between the pin and the medullary canal is easier in small dogs. It has been reported that intramedullary pins are satisfactory for shaft fractures of the femur in small dogs and cats [7]. As Boyd has said, an intramedullary pinning is justified only in situations when its mechanical advantages from the stand point of the stress involved outweigh the biological disadvantages and when rotation can be controlled. From a biomechanical point of view, the callus decreases the lever arm which tends to stretch the fracture, which is why the callus will be even larger than the home is unstable [8]. Implants failure from fatigue fracture is not common with intramedullary pinning because the location of an intramedullary pin in the centre of the shaft tends to spare some of the bending forces responsible for fatigue failure and the effect of the law of wolf which is very favorable by the intramedullary pinning.

\section{Conclusions}

We are now convinced that a serious study from dogs could open huge doors therapeutic and allow us to open a door for biological fixation. The intramedullary pinning offers a perfect alignment and rigid fixation of the fracture. This allowed early perspectives: 


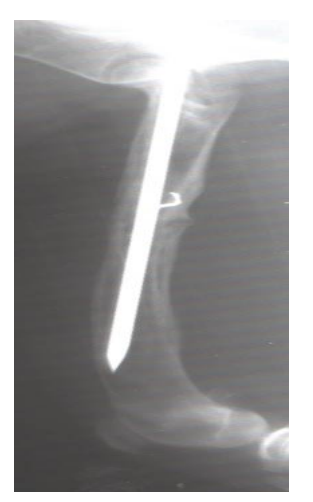

Figure 8. A radiograph at two months showing a complete integration of bone with significant narrowing of callus volume.

- Application of other imaging means for assessment of fracture repair;

- Histological study of fracture healing;

- Fracture repair by intramedullary nailing.

\section{Acknowledgements}

My thanks addressed to the radiology centers of Tiaret (Algeria) (Dr Efret and Dr Chikhaoui), for all authors of this article for their true help, mainly Dr Boudra Abdellatif for his ideas and suggestions in orthopedic surgery.

\section{References}

[1] Brinker, W.O., Piermattei, D.L. and Flo, G.L. (1994) Le Manuel d'orthopédie et de traitement des fractures des petits animaux. 2nd Edition, Point Vétérinaire, Maisons Alfort, 9-137.

[2] Wagner, M. and Frigg, R. (2006) Internal Fixators. Thieme Medical Publishers, New York.

[3] Beale, B. (2004) Orthopedic Clinical Techniques Femur Fracture Repair. Clinical Techniques in Small Animal Practice, 19, 134-150. http://dx.doi.org/10.1053/j.ctsap.2004.09.006

[4] Autefage, A. (1992) Consolidation des fractures, encyclopédie vétérinaire, Paris. Orthopédie, 3100, 1-8.

[5] Fossum, T.W. (2007) Small Animal Surgery. 3rd Edition, Elsevier, Mosby, 935-1005.

[6] Duhautois, B. (1993) L’enclouage verrouillé en chirurgie vétérinaire de la conception aux premiers cas cliniques. Practice Medicale et Chirurgiacl de l'animal de Compagnie, 28, 657-683.

[7] Phillips, I.R. (1979) A Survey of the Bone Fractures in the Dog and Cat. Journal of Small Animal Practice, 20, 661674. http://dx.doi.org/10.1111/j.1748-5827.1979.tb06679.x

[8] Piermattei, D.L., Flo, G.L. and Decamp, C.E. (2006) Handbook of Small Animal Orthopedics and Fracture Repair. 4th Edition, Saunders, Philadelphia, 25-159. 